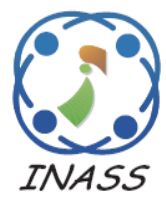

\title{
Adaptive Fuzzy Controller Based Self Regulated Reference Stator Flux Estimator of Direct Torque Control for Three Level Inverter Fed IPMSM
}

\author{
Danduprolu Kiran Kumar ${ }^{1 *}$ \\ Gaddam Tulasi Ram Das ${ }^{1}$ \\ ${ }^{1}$ Department of Electrical and Electronics Engineering, \\ Jawaharlal Nehru Technological University Hyderabad College of Engineering Hyderabad, \\ Hyderabad - 500085, Telangana, India \\ * Corresponding author's Email: kirannkumar9@gmail.com
}

\begin{abstract}
The paper suggests a new direct torque control approach for Interior Permanent Magnet Synchronous Machine (IPMSM) with adoption of space vector modulation topology based three level inverters (TH-LI).The proposed control strategy is critically evaluated and compared with Conventional DTC (CDTC) of drive that it is utilized the Fuzzy Logic Controller (FLC) as speed feedback loop controller for each drive through Simulink/MATLAB Platform. The key idea for the proposed control strategy is incorporated by Self Regulated Reference Stator Flux (SRRSF) estimator which is implemented with the error signal of torque regulator and reference stator flux. Further, the SRRSF estimator is interfaced with Adaptive Fuzzy Logic Interfacing System Controller (AFLISC). In order to investigate the effectiveness of the proposed technique, the steady state and dynamic state responses under variable motor speed with variable load is performed. The obtained simulation results are affirmed that the torque and stator flux ripples are significantly minimised for entire speed range. However, the torque and flux ripples of proposed DTC is compared numerically with CDTC that an average ripple reduction of $79.9 \%$ for torque and $62.47 \%$ for flux under load conditions is found. Thus, the performance of aforementioned proposed control strategy of IPMSM drive is demonstrated that the drive achieved high and accurate control of torque under the steady and dynamic state conditions.
\end{abstract}

Keywords: Direct torque control, Interior permanent magnet synchronous machine, Reference stator flux.

\section{Introduction}

High performance ac drives and multilevel inverters are vigorous demand in many essential applications such as computer numerically controlled machine tools, ship propulsions, electric aircraft, hybrid electrical vehicle and renewable energy sources $[1,2]$. In which, the movable controllers are required to reflect based on instructions and satisfy the robustness over the uncertainties of drives. Thus, PMSM leads towards the motion control applications due to perfect field segmentation and exhibit constant flux region. Subsequently, the performance control operation of drive is enfeebled with unpredictable variable changes, uncertainties and nonlinear dynamics of the system.
Therefore, The DTC is considered as a viable control strategy for PMSM to achieve the robustness from external load disturbances and parameter changes [3].

The Conventional DTC (CDTC) is addressed as widespread control technique further applied to several machines in various industrial speed applications. In CDTC, the current controller replaced with explicit torque and flux regulators that are derived from machine modelled. Additionally, DTC is operated in speed control operation without the rotor position. With intent simplicity of DTC, the adequate torque control performances are significantly achieved under both steady state and dynamic control conditions [4, 5]. However, the CDTC despite wide prominent problems such high torque pulsations and the variable switching frequency. Thus, the obtained control performance of 
CDTC of drive is associated with undesirable responses at various speed conditions.

In recent years many researchers have proposed various DTC approaches based on duty cycle calculations [6-8]. In which, the appropriate voltage vectors are applied to AC motors for entire control operations at any circumstance. The torque and flux are not controlled effectively and for reduction of torque ripples is focused only in this approach that is main limitation of any duty cycle-based DTC technique. Hence, the proposed DTC controls the torque and flux accurately.

The authors [9] have proposed that the magnitude of reference stator flux is computed mathematically by approximately, whereas the proposed DTC is self corrected by using adaptive fuzzy system. Thus, the flux is accurately controlled to achieve stable and robust performance of a PMSM drive under different operating conditions, A self tuning approach is proposed in this work.

In recent developments [10], the researchers have proposed self-computing the modified reference stator flux for DTC of Induction motor. But this DTC technique is adopted to special machine such as PMSM with three level inverter which increase degree of freedom to apply voltage vectors and PI controller is replaced by FLC in speed feedback loop in the proposed work.

Therefore, a rigorous research is done on DTC algorithm. In the way to become an advanced DTC algorithm for AC drives, DTC expanded in the area of power electronic semiconductors such as multilevel inverter topologies. In fact, the key factor of the control technique is adopted by Space Vector Pulse Width Modulation (SVPWM) topology for Three Level Inverter (TH-LI). The TH-LI fed DTC of SVPWM is capable to handle the constant switching frequency. Consequently, the TH-LI is increased the degree of freedom to select relative voltage vectors $[11,12]$. Initially, the performance of IPMSM drive with PI controller is still influenced from aforementioned limitations of Conventional DTC. The FLC was able to enhance the problems of nonlinear drive which is associated with uncertainties of the IPMSM [13, 14]. Hence, TH-LI fed DTC of drive with FLC considerably reduced the ripples in electromagnetic torque, stator flux and three phase currents.

Subsequently, a modified DTC is adopted for controlling IPMSM with multilevel inverter that the proposed DTC embodied with self-regulated reference flux estimator. The self modified reference stator flux is obtained from the instructed electromagnetic torque and reference stator flux for reducing the ripples in motor torque. As subsequently, the flux is more precise to control in the new DTC which leads to reduce the current THD and improve the efficiency of the motor $[9,15]$. Further, the self tuning of flux estimator is interfaced with AFLISC.

The AFLISC is a self tuned controller which is powerful intelligent control approach that performs two major activities such as adaptive fuzzy logic controller (AFLC) and a learning mechanism. Moreover, the learning system is provided the feedback information of the system. The AFLC is implemented with the scaling factor tuning technique. Therefore, three scaling factors are considered such as two inputs that is the command torque and reference stator flux, and then one output is auto regulated reference stator flux $[16,17]$. Hence, the scaling factors are continuously tuned until to satisfy the need for the fuzzy interfacing system.

In fact, the main key factor of the proposed control is the membership functions for the reference flux and self corrected reference flux are applied symmetrically and continuously for achieving stable performance of IPMSM drive at steady and dynamic state operations. However, the obtained results of proposed DTC of the drive is revealed with low robustness against the motor parameters changes compare to the CDTC of IPMSM under variable motor speed with variable load. Therefore, the proposed DTC of IPMSM controls the torque and flux effectively with minimisation of ripples in torque and stator flux responses.

This paper is organized as follows: In Section 2 describes the dynamic modeling justification of PMSM. Section 3 addresses the implementation of speed feedback circuit controller by using fuzzy logic controller which includes the demonstration of fuzzy interfacing rules with corresponding membership functions. In section 4, it presents the proposed technique for three level DTC. Section 5 describes the implementation of proposed DTC for IMPSM which is verified the effectiveness of proposed drive by comparing the obtained simulation results with Conventional DTC and followed by the conclusion.

\section{Dynamic model of IPMSM}

The dynamic control model of IPMSM is derived in rotor reference frame due to sinusoidal quantities of stationary reference frame maintained constant under steady state [18] condition that synchronously rotating rotor reference presented in Fig. 1.

Hence, the state equations are described from the equivalent circuit of IPMSM drive system in $d, q$ frame [19] which is represented as in Figs. 2 (a) and 


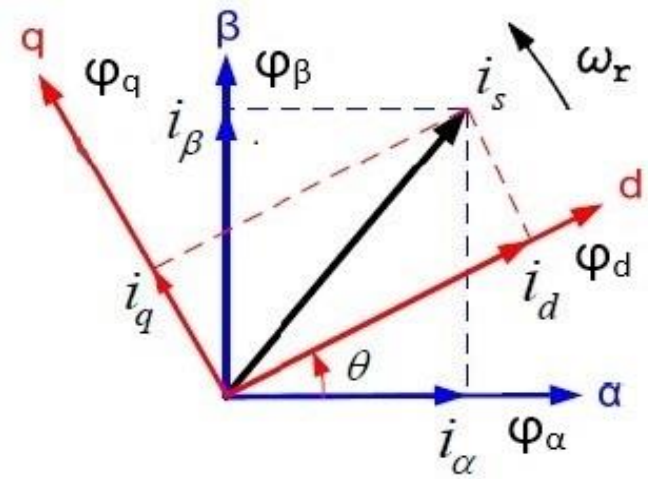

Figure.1 Orientation of different reference frame

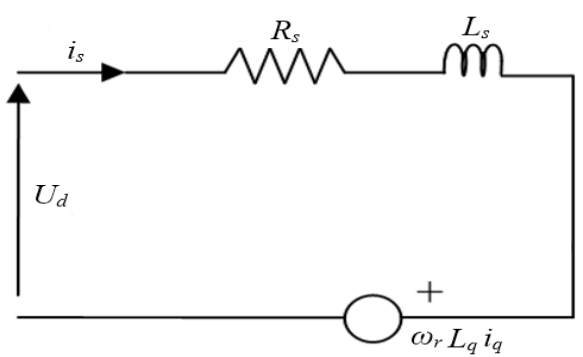

(a)

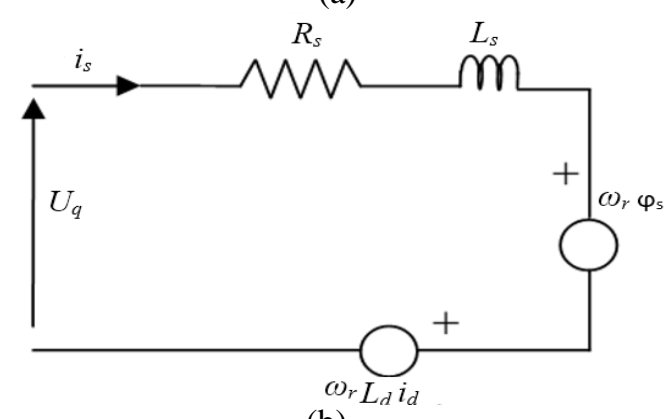

(b)

Figure.2 Equivalent circuit of an IPMSM: (a) q axis circuit and (b) d axis circuit

(b) respectively and subsequent expressions [20] as follows:

$$
U_{s}, d q=R_{s} i_{s}, d q+\frac{d}{d t} \varphi_{s}, d q+\mathcal{F} \varphi_{s}, d q
$$

Where $\mathcal{F}=\left[\begin{array}{cc}0 & -\omega_{r} \\ \omega_{r} & 0\end{array}\right], \omega_{r}$ is rotor angular speed, $R_{S}$ is stator equivalent resistance,

$\varphi_{s}, d q=\left[\begin{array}{ll}\varphi_{d} & \varphi_{q}\end{array}\right]^{T}$ is stator flux vector,

$U_{s}, d q=\left[\begin{array}{ll}U_{d} & U_{q}\end{array}\right]^{T}$ and

$i_{s}, d q=\left[\begin{array}{ll}i_{d} & i_{q}\end{array}\right]^{T}$ are stator voltage and current vectors respectively.

The estimated electromagnetic torque is expressed [21]:

$$
T_{e}=\frac{3 P}{2}\left(\varphi_{d} i_{q}-\varphi_{q} i_{d}\right)
$$

Where $\mathrm{P}$ is number of poles

However, the vector of stator flux is expressed:

$$
\varphi_{s}, d q=\mathcal{G} i_{s}, d q+\varphi_{r}, d q
$$

$\mathcal{G}=\left[\begin{array}{cc}L_{d} & 0 \\ 0 & L_{q}\end{array}\right]$, here $\mathcal{G}$ is direct and quadrature axis inductances matrix and $\varphi_{r}, d q=\left[\begin{array}{ll}\varphi_{\mathcal{F}} & 0\end{array}\right]^{T}$, $\varphi_{\mathcal{F}}$ is the amplitude magnetic flux of IPMSM.

\section{Design a fuzzy logic controller of speed loop for reducing torque and flux ripples}

In order to improve the robustness of variable speed drives, the fuzzy logic controller (FLC) is most viable for handling the uncertainties which influenced due to PI controller of nonlinear systems. The FLC significantly satisfied the motor control operations without exact modelling and parameters. With intent advantages like easy for computation and overlapping, the triangular membership functions are adopted for fuzzification, fuzzy reasoning through mapping that solution is achieved by symmetrical membership functions is globally applicable [22].

In general, the dynamic control operation of a nonlinear system is illustrated as expression:

$$
T_{\text {Ref }}=k_{p} e_{s}(t)+k_{i} \int e_{s}(t) d t
$$

Where $k_{p}$ and $k_{i}$ are the proportional and integral gains of PI controller and $e_{s}$ is speed error respectively.

$$
\begin{aligned}
& \frac{d T_{R e f}}{d t}=k_{p} \frac{d e_{s}(t)}{d t}+k_{i} e_{s}(t) \\
& \Delta T_{R e f}=k_{p} \Delta e_{s}+k_{i} e_{s}
\end{aligned}
$$

Where, $\Delta T_{R e f}$ is error variation which is directly proportional to speed error $e_{S}$ and change in speed error $\Delta e_{s}$. However, these parameters are presented as:

$$
\begin{gathered}
e_{S}(k)=\omega_{R e f}(k)-\omega_{E s t}(k) \\
\Delta e_{S}=\frac{e_{S}(k)-e_{S}(k-1)}{T_{S}}
\end{gathered}
$$

Where $\omega_{\text {Ref }}(k)$ and $\omega_{E s t}(k)$ are the reference and actual rotor speed of IPMSM respectively. The $e_{s}(k)$ and $e_{s}(k-1)$ are the present and past speed error of PI speed controller and Ts is sampling period respectively.

In this paper, the input and output variables of FLC scaling factor range is represented $(-1.0,1.0)$ in per units [23]. In fuzzification, the input and output crisp values are transformed into membership functions (MFs) based on linguistic rules such as 
Positive Big (PB), Positive Medium (PM), Positive Small (PS), Zero Equal (ZE), Negative Small (NS), Negative Medium (NM), and Negative Big (NB) [24]. The desire control performances of IPMSM is obtained with careful design of the inference rules that rules enlisted in the table 1 and corresponding MFs of the input and the output variable which is the key part of the FLC is illustrated in Figs. 3 (a) and (b) respectively.

As consequently, the defuzzification is implemented by center of gravity approach that is presented as expression below:

$$
\Delta T_{R e f}=\frac{\sum_{n=1}^{36} u_{a 1} e_{S}(t) u_{a 2} \frac{d e_{n}}{d x} c_{n} s_{n}}{\sum_{n=1}^{36} u_{a 1} e_{S}(t) u_{a 2} \frac{d e_{n}}{d x} c_{n} s_{n n}}
$$

Where $S_{n}$ is the decision of the rule-based surface function, $C_{n}$ is the decision of the rule-based centre of gravity function and $\mathrm{n}$ is the number of fuzzy inference rules.

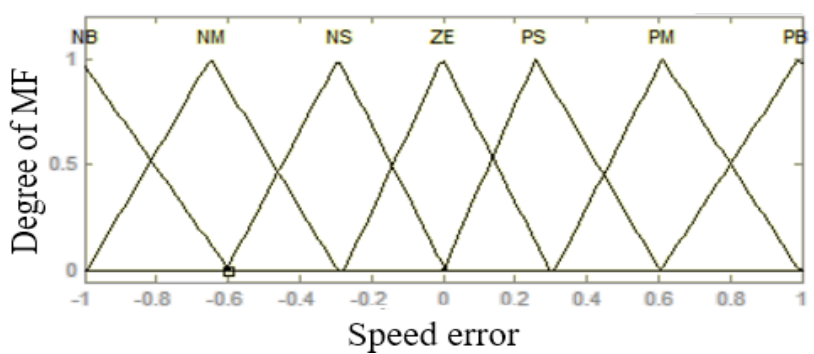

(a)

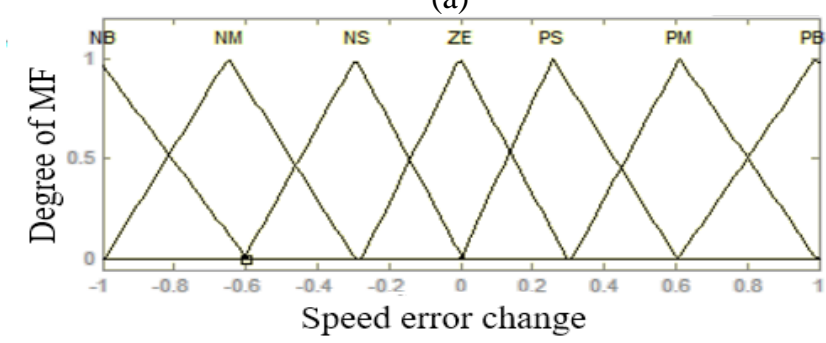

(b)

Figure.3 Membership Functions: (a) speed error and (b) change in speed error

Table 1. Fuzzy inference rules

\begin{tabular}{rlllllll}
\hline $\begin{array}{c}\Delta \mathbf{e}_{\boldsymbol{s}} \\
\boldsymbol{e}_{\boldsymbol{s}}\end{array}$ & NB & NM & NS & ZE & PS & PM & PB \\
\hline NB & NB & NB & NB & NB & NM & NS & ZE \\
\hline NM & NB & NB & NB & NM & NS & ZE & PS \\
\hline NS & NB & NB & NM & NS & ZE & PS & PM \\
\hline ZE & NM & NS & NS & ZE & PS & PM & PB \\
\hline PS & NM & NS & ZE & PS & PM & PB & PB \\
\hline PM & NS & ZE & PS & PM & PB & PB & PB \\
\hline PB & ZE & PS & PM & PB & PB & PB & PB \\
\hline
\end{tabular}

\section{Design an adaptive fuzzy logic interfacing of self regulated reference stator flux}

In order to improve the stability and efficiency of IPMSM, the stator flux plays a vital role for designing of DTC approach. Moreover, the system is operated at no load to full load that the flux leads to generate the high ripples in the torque. In addition, the system is operated at constant flux which included to produce more core losses which may also cause to reduce efficiency of system. Therefore, to achieve the desired performance control operations of the drive, a Self-Regulated Reference Stator Flux Estimator (SRRSF) is designed for TH-LI fed DTC of IPMSM. Here, the SRRSF is recalculated from the error signal of torque and reference stator flux as presented in Fig. 4. Furthermore, the SRRSF is implemented with adaption of an Adaptive Fuzzy Logic interfacing approach [10].

Where, $\mathrm{T}_{\text {Ref }}$ and $\mathrm{T}_{\mathrm{Est}}$ are the reference electromagnetic torque and estimated torque of the motor respectively. Where $\varphi_{\text {Ref }}, \varphi_{\text {Est }}, \Delta \varphi_{\text {Ref }}$ and $M \varphi_{\text {Ref }}$ are the stator reference flux, estimated stator flux, the corrected reference flux and modified reference flux responses of the drive respectively. Subsequently, $\mathrm{H}_{\varphi}$ is stator flux error value.

The Adaptive Fuzzy Logic Interfacing System Controller (AFLISC) is adopted to obtain the robustness and stability responses of closed loop drive. Generally, the AFLISC is established with two major operations such as an adaptive fuzzy logic controller (AFLC) and a learning mechanism. In which, the tuning feedback information is obtained from the learning operation that used by AFLC. In AFLISC, the scaling factor tuning technique is adopted [24, 25]. Thus, three scaling factors are selected such as two inputs: torque error $\left(\mathrm{H}_{\mathrm{T}}=\mathrm{T}_{\text {Ref }}-\right.$ $\left.\mathrm{T}_{\mathrm{Est}}\right)$ and the reference flux from the reference flux

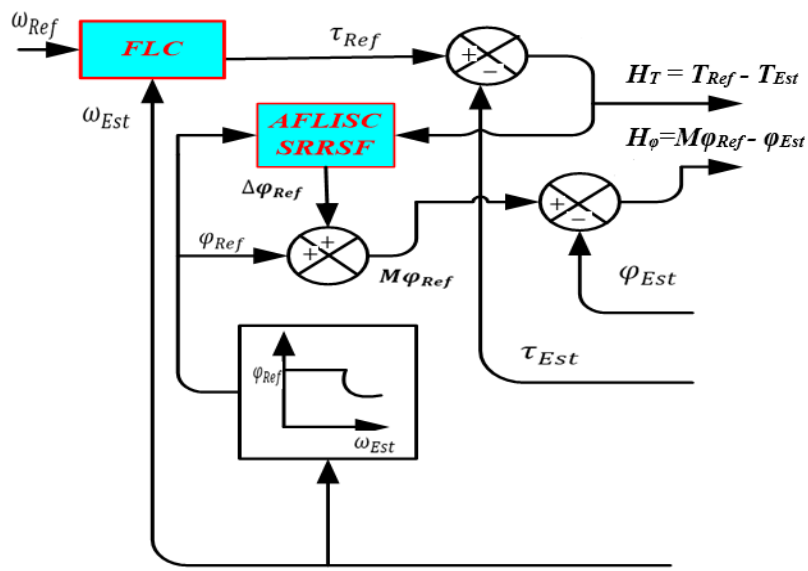

Figure.4 Block diagram of proposed control technique 


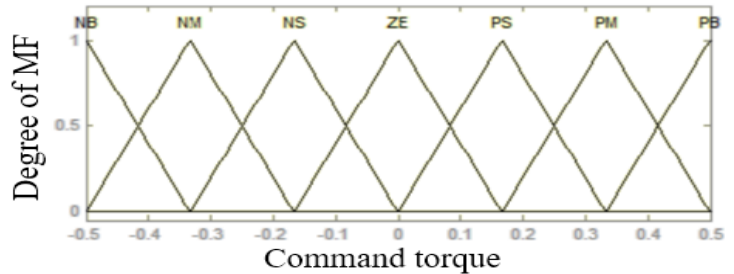

(a)

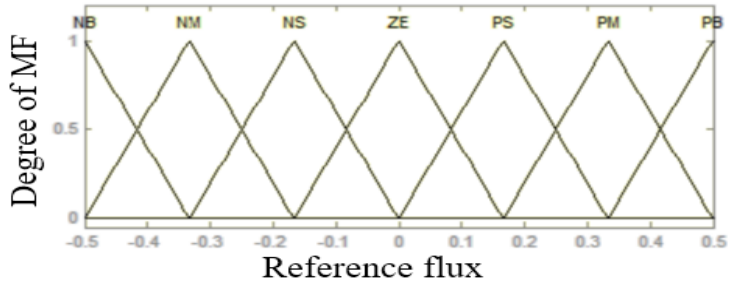

(b)

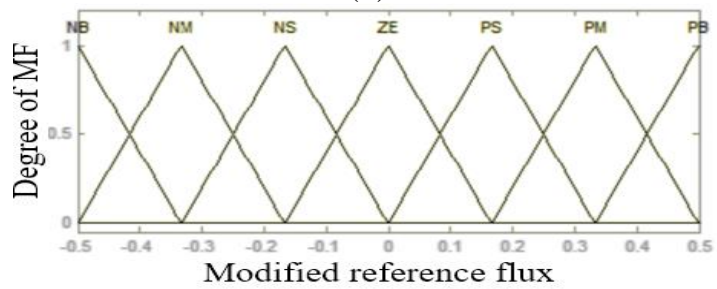

(c)

Figure.5 Scaling Factor based MFs: (a) torque error (b) reference stator flux (c) modified stator flux

estimator, and then one output that is the automatic corrected reference flux. However, the scaling factors are continuously tuned until to satisfy the requirement of the fuzzy interfacing system to achieve the control performance of IPMSM for steady and dynamic state. From the Figs. 5 (a), (b), and (c) show the membership functions of Fuzzy Adaptive Controller using input and output Scaling Factors based on linguistic rules that are shown in aforesaid table.

\section{Simulation Results and Discussions}

In order to evaluate the effectiveness of the proposed DTC technique, several digital simulations are carried out as described in Fig. 6 through the MATLAB/Simulink Platform. The obtained simulation results of the proposed control method are critically investigated and compared against the THLI of CDTC for IPMSM using FLC speed feedback controller under variable speed and various loads are applied at different instants of time for overall speed range. However, the comparative analysis is performed between the TH-LI of CDTC for IPMSM using FLC and CDTC of IPMSM with PI controller under various motor speed and load conditions in previous research [26]. The nominal IPMSM parameters are derived from the motor identified data: Stator resistance (Rs) is $7.2 \Omega$, direct axis $\left(\mathrm{L}_{\mathrm{d}}\right)$ and quadrature axis inductance $\left(\mathrm{L}_{\mathrm{q}}\right)$ are $6 \mathrm{mH}$ and
$11 \mathrm{mH}$, rotor moment of inertia $\left(\mathrm{B}_{0}\right)$ is 0.000482 and friction factor $\left(\mathrm{J}_{0}\right)$ is 0.000392 respectively [26][27]. The control sampling time for DTC based drive is taken as $50 \mu \mathrm{sec}$.

Further, the proposed SRRSF estimator-based DTC approach is demonstrated that the ripples in torque and flux are significantly eliminated at steady and dynamic state control conditions against the conventional DTC of IPMSM using TH-LI. In order to conduct the comparison of the aforementioned control strategies, the motor and control parameters are kept the same under similar test conditions. In fact, the steady state and dynamic control operations of proposed control strategy system is demonstrated with fast transient state at dynamic control performances.

In the test scenario, a comprehensive analysis is conducted between the conventional TH-LI of DTC and Proposed adaptive fuzzy based SRRSF for DTC. In which, the FLC is utilised as speed feedback controller for each drive at different operating conditions. The proposed control algorithm of drive is operated with the command value of the speed at $250 \mathrm{rads} / \mathrm{sec}$. with no load till $0.1 \mathrm{sec}$.The starting current of the drive is included with high ripples. However, the actual rotor speed of proposed system is reached to the reference speed without overshoot that leads towards the reduction of the current ripples in stator current.

Subsequently, a torque load $\mathrm{T}_{\mathrm{L}}=1.6 \mathrm{Nm}$ is applied to IPMSM at $0.1 \mathrm{sec}$. Whereas, the speed response of the proposed control approach stabilised with reference speed track with a smallest dip. Furthermore, the performance control operation of the drive with proposed SRRSF regulator is also investigated at the speed changing operation. Thus, the reference speed track steps are increased from 250 $\mathrm{rads} / \mathrm{sec}$. to $300 \mathrm{rads} / \mathrm{sec}$., $300 \mathrm{rads} / \mathrm{sec}$. to 350 $\mathrm{rads} / \mathrm{sec}$., $350 \mathrm{rads} / \mathrm{sec}$. to $400 \mathrm{rads} / \mathrm{sec}$. and 400 $\mathrm{rads} / \mathrm{sec}$. to $450 \mathrm{rads} / \mathrm{sec}$. and then variable torque load such as $1.7 \mathrm{Nm}$ at $0.3 \mathrm{sec}, 1.8 \mathrm{Nm}$ at $0.5 \mathrm{sec}, 1.9$ $\mathrm{Nm}$ at $0.7 \mathrm{Sec}$ and $2 \mathrm{Nm}$ at $0.9 \mathrm{sec}$ are applied for the entire speed range that evidence represented as in Fig. 7. The speed responses observed that the modified DTC with adaptive fuzzy based SRRSF perform quick load disturbance rejection against the conventional control strategy with three level of IPMSM.

The electromagnectic torque and stator flux responses of the drive with no load, a variable torque load disturbance at various instants and the steady state and dynamic state operations of DTC drive are depicted in Figs. 8 and 9 respectively. The machine load being increased from $1.6 \mathrm{Nm}$ to $2 \mathrm{Nm}$ at various 


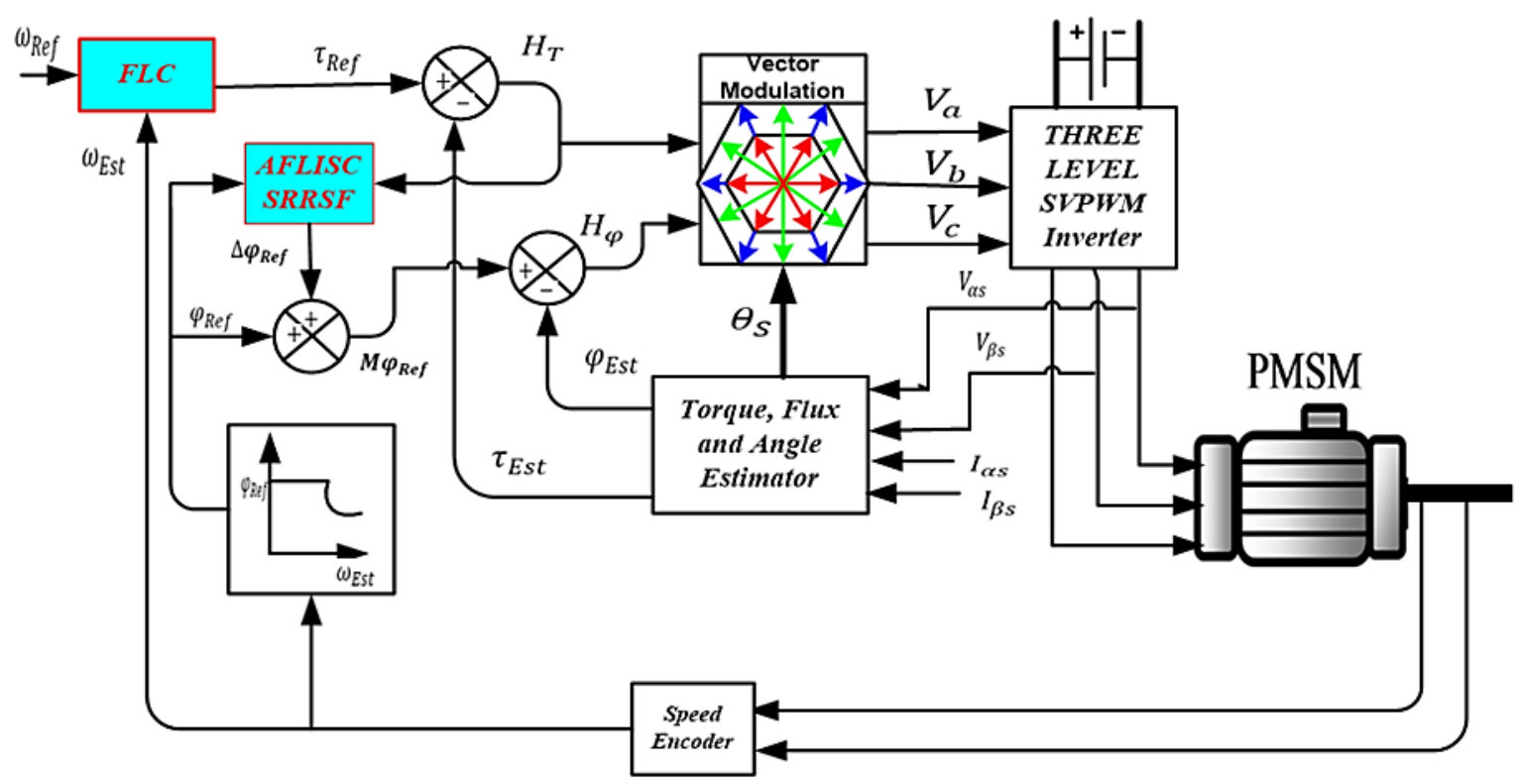

Figure. 6 Simulink orientation block diagram of TH-LI fed DTC of IPMSM

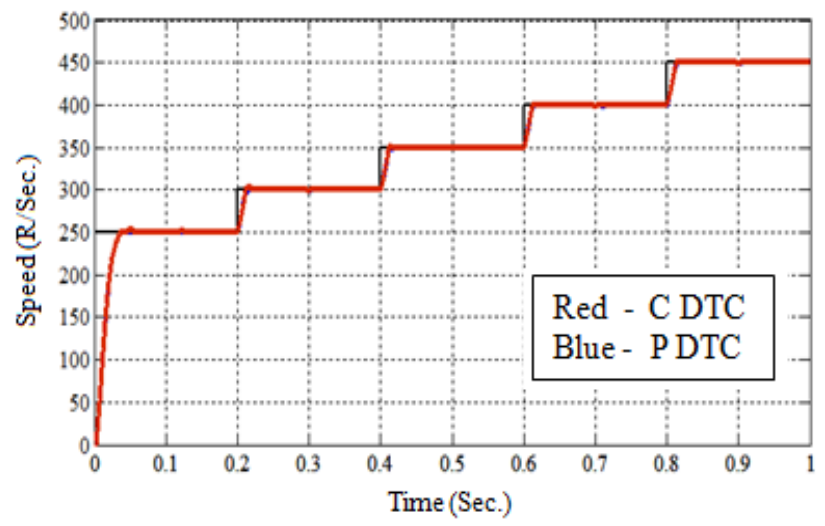

Figure. 7 Comparison of speed of CDTC and PDTC for IPMSM

instants of time period for entire speed region. The electromagnetic torque and stator flux ripples are increased as compared to no-load condition for CDTC and proposed DTC respectively.

However,the performance quantitative indices are summarised for the percentage of ripples in torque and stator flux for each DTC method under various speed and variable load torque condition.

Thus, the proposed DTC with adaptive fuzzy controller of SRRSF regulator strategy reached to the reference torque and flux associated with less ripples than other control strategy that are illistrated graphically as in Fig. 10. Additionally, the SRRSF adopted DTC is exhibited superior steady state and transient state respose in torque and stator flux.In adaptive fuzzy based TH-LI of DTC,the instructed stator flux of $0.53 \mathrm{~Wb}$ is changed with respect to load operation.The error signal of electromagnectic torque is considered as an objective function and then the flux is seccessive step changed. Subsequantly,the stator flux value is varied with respect to the initial to final value of load torque. Thus, the stator flux optimised the convergence of speed and ripples.

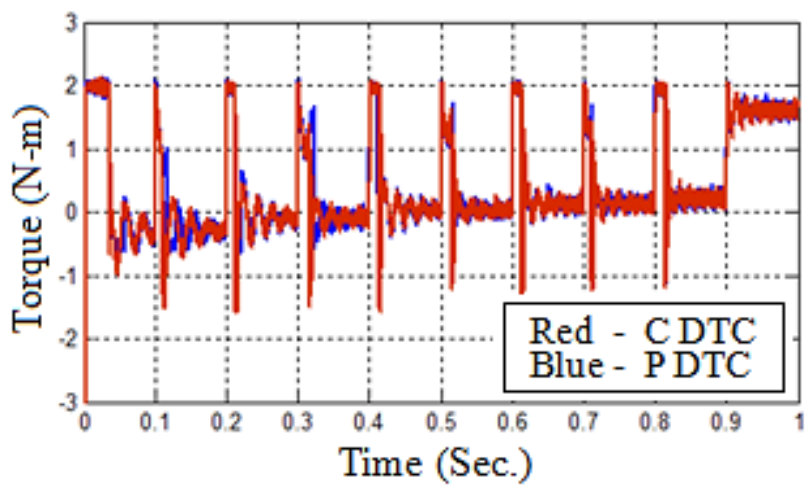

(a)

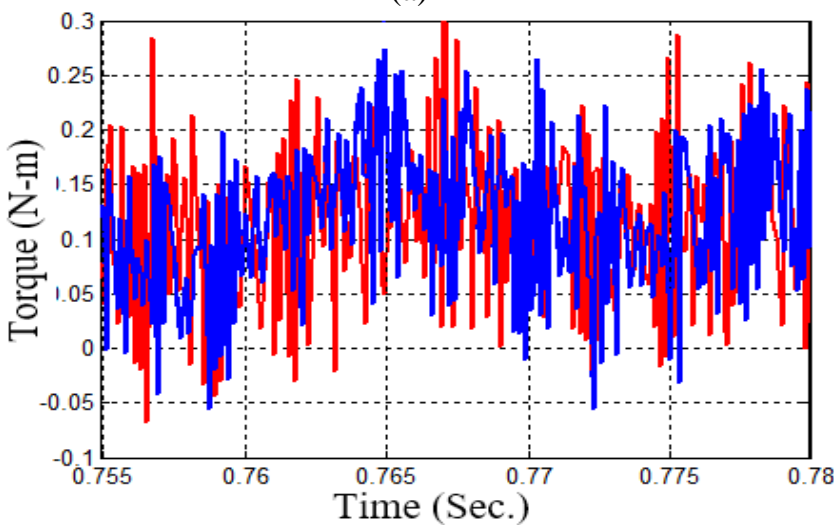

(b)

Figure. 8 Comparison of Torques of CDTC and PDTC for IPMSM: (a) normal mode and (b) enlarged mode 


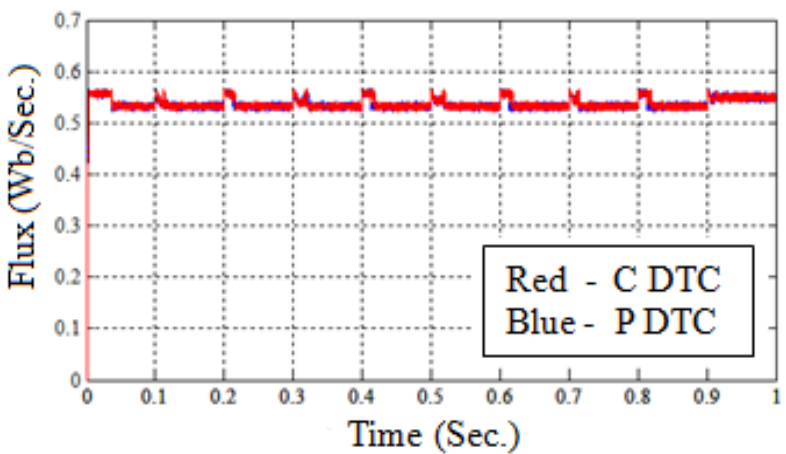

(a)

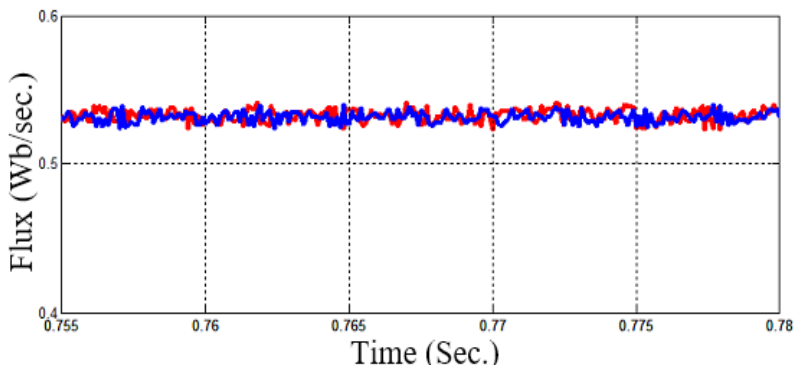

(b)

Figure. 9 Comparison of flux of CDTC and PDTC for IPMSM: (a) normal mode and (b) enlarged mode

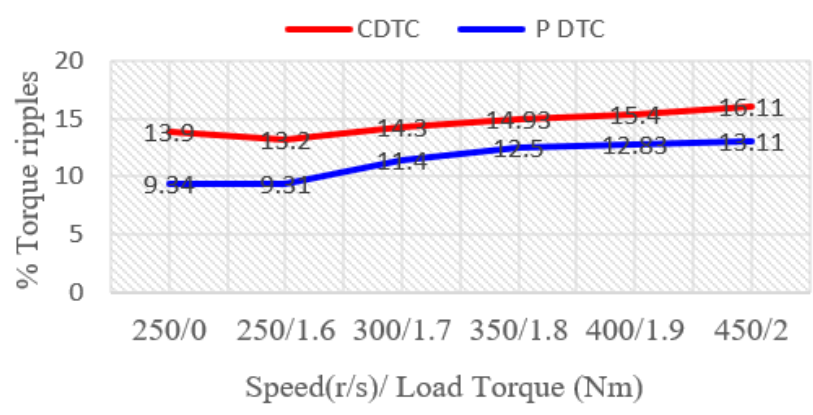

(a)

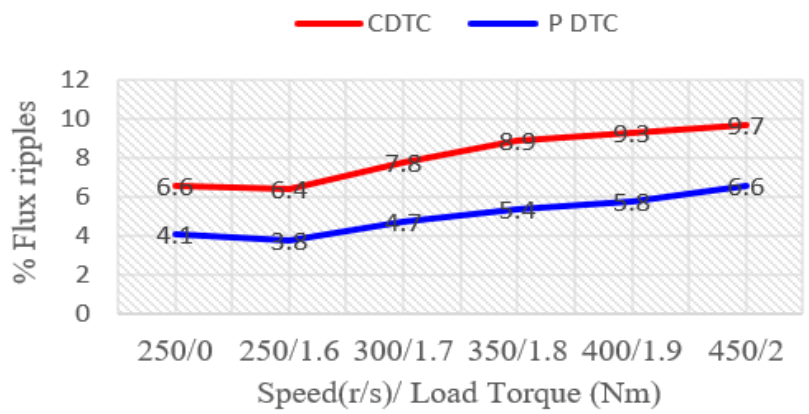

(b)

Figure. 10 Comparison of performance indices of: (a) \% torque ripples and (b) \% flux ripples

The speed response of the proposed DTC for IPMSM is increased from $350 \mathrm{rads} / \mathrm{sec}$. to 400 $\mathrm{rads} / \mathrm{sec}$. at $0.6 \mathrm{sec}$. whereas a sudden torque load of $\mathrm{T}_{\mathrm{L}}=1.9 \mathrm{Nm}$ is injected at $0.7 \mathrm{sec}$., the stator current ripples are improved when compared to the CDTC of

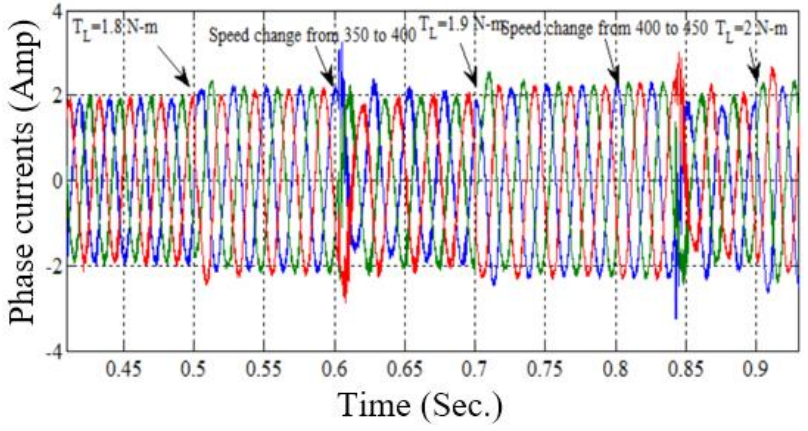

(a)

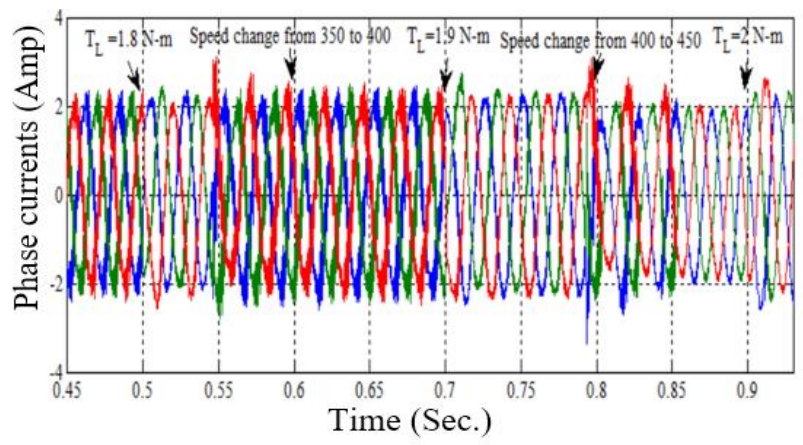

(a)

Figure. 11 Phase currents of IPMSM using: (a) PDTC (b) CDTC

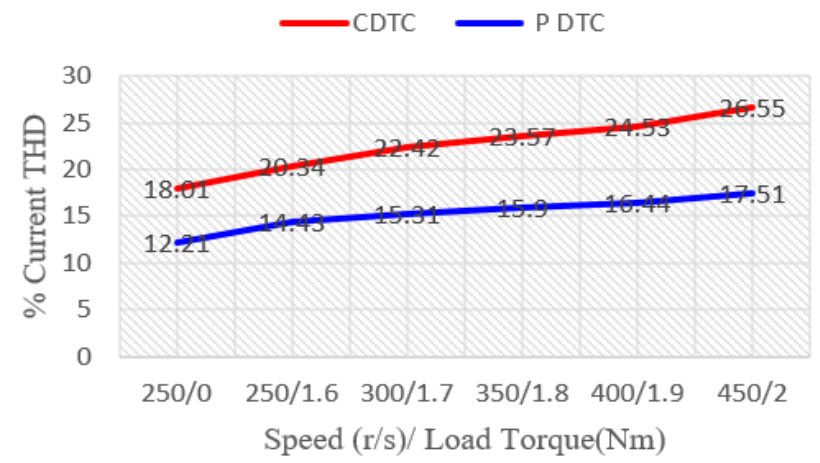

Figure. 12 Comparison of performance indices of $\%$ THD of Stator currents

drive with TH-LI that evidence is presented in Fig. 11. In case of the IPMSM with SRRSF regulator applied load of $1.9 \mathrm{~N}-\mathrm{m}$, the current THD is $16.44 \%$. However, the CDTC of IPMSM is associated with THD of current is $24.53 \%$ that is exploited from the graphical comparison that represented in Fig. 12.

\section{Conclusions}

In this paper, an adaptive fuzzy interfaced SRRSF based DTC algorithm is developed for three level inverter of Interior Permanent Magnet Synchronous Machine for controlling torque and flux accurately. The adaptive fuzzy controller of SRRSF is provided the self corrected stator reference flux error value that is obtained from the difference between the command torque and the reference stator flux. As subsequently, 
the magnitude of reference stator flux is changed which exhibited the stable and robustness performances of the drive at various speed and load scenarios.

With intent of aforesaid features, the adaptive fuzzy controlled SRRSF estimatorbased DTC of IPMSM is proposed which exhibited with prominent controlled torque and flux of the motor. Consequently, the effectiveness of proposed control of IPMSM is clearly investigated that the drive is performed, tested under various speed increment approach and the obtained results are demonstrated with minimisation of torque and flux ripples at steady state and dynamic control operations compared to the CDTC of IPMSM. However, the proposed DTC is achieved fast dynamic performance at transient control operation.

\section{References}

[1] F. Niu, B. Wang, A. Babel, K. Li and E.G. Strangas, "Comparative evaluation of direct torque control strategies for permanent magnet synchronous machines", IEEE Transactions on Power Electronics, Vol.31, No.2, pp.1408-124, 2016.

[2] Q. An, J. Liu, Z. Peng, and L. Sun, "Dual-Space Vector Control of Open-End Winding Permanent Magnet Synchronous Motor Drive Fed by Dual Inverter", IEEE Transactions on Power Electronics, Vol. 31, No. 12, pp.83298342, 2016.

[3] J. Solsona, M.I. Valla, and C. Muravchik, "Nonlinear Control of Permanent Magnet Synchronous Motor with Disturbance Torque Estimation", IEEE Transactions on Energy Conversion, Vol. 15, No. 2, pp.163-168, 2000.

[4] I. Takahashi and Naguchi, "A new quick response and high efficiency control strategy of an induction motor", IEEE Transaction on Industry Applications, Vol.22, No.5, pp.820$827,1986$.

[5] M. P. Kazmierkowski and A. B. Kasprowicz, "Improved direct torque and flux vector control of PWM inverter-fed induction motor drives", IEEE Transactions on Industrial Electronics, Vol.42 No.4, PP.344-350, 1995.

[6] Y. Ren, Z.Q. Zhu, and J. Liu, "Direct torque control of permanent magnet synchronous machine drives with a simple duty ratio regulator", IEEE Trans. Ind. Electron., Vol. 61, No. 10, pp. 5249-5258, 2014.
[7] K. Jezernik, R. Horvat, and M. Curkovic, "A Switching Control Strategy for the Reduction of Torque Ripple for PMSM", IEEE Transactions on Industrial Informatics, Vol.9, No.3, pp. 12721279, 2013.

[8] W. Chen, Y.Y. Zhao, Z.Q. Zhou, Y. Yan and C.L. Xia, "Torque Ripple Reduction in ThreeLevel Inverter Fed Permanent Magnet Synchronous Motor Drives by Duty Cycle Direct Torque Control Using an Evaluation Table", Journal of Power Electronics, Vol. 17, No. 2, pp. 368-379, 2017.

[9] Y. Zhang and J. Zhu, "A novel duty cycle control strategy to reduce both torque and stator flux ripples for DTC of permanent magnet synchronous motor drives with switching frequency reduction", IEEE Transactions Power Electron., Vol. 26, No. 10, pp. 3055-3067, 2011.

[10] S. S. Kumar, R. J. Xavier, and S. Balamurugan, "Development of ANFIS-based reference flux estimator and FGS-tuned speed controller for DTC of induction motor", Journal for Control, Measurement, Electronics, Computing and Communications, Vo.59, No. 01, pp.11-23, 2018.

[11] D. Mohan, X. Zhang, and G. H. B. Foo, "ThreeLevel Inverter-Fed Direct Torque Control of IPMSM with Torque and Capacitor Voltage Ripple Reduction", IEEE Transactions on Energy Conversion, Vol. 31, No. 4, pp.15591569, 2016.

[12] U. Kumar, V. Patil, H.M. Suryawanshi, and M. M. Renge, "Closed-loop hybrid direct torque control for medium voltage induction motor drive for performance improvement", IET Power Electronics, Vol. 7, No. 1, pp. 3140,2014.

[13] H. Sudheer, B. Sarvesh, and S.F Kodad, "Improved Fuzzy Logic based DTC of Induction machine for wide range of speed control using AI based controllers", Journal of Electrical Systems, Vol.12 No.2, pp.301-314, 2016.

[14] W. Xingjian and W. Shaoping, "Adaptive Fuzzy Robust Control of PMSM with Smooth Inverse Based Dead-zone Compensation", International Journal of Control, Automation and Systems, Vol.14, No. 2, pp. 378-388, 2016.

[15] M.A. Ibrahim and N.I. N. Rumzi, "Simple flux regulation for improving state estimation at very low and zero speed of a speed sensor less direct torque control of induction motor", IEEE Transactions Power Electron.Vol.31 No. pp.3027-3035,2016.

[16] E. Hady, A. Maksoud, M.M. Khater, and S. M. Shaaban, "Adaptive Fuzzy Logic PI Control for Switched Reluctance Motor Based on 
Inductance Model", International Journal of Intelligent Engineering and System, Vol.10, No.4, pp.41-49, 2016.

[17] J. M. Jou, P. Y. Chen and Y. S. Fu, "An Adaptive Fuzzy Logic Controller: Its VLSI Architecture and Applications", IEEE Transactions on Very Large-Scale Integration (VLSI) Systems, Vol. 8, No. 1, 2000.

[18] G. T. R. Das and D. K. Kumar, "Fuzzy Logic Controller based performances of SPMSM fed with improved Direct Torque Control", International Journal of Renewable Energy Research Vol.9, No.3, pp.1346-1354, 2019.

[19] R. Aruna and S. M. Sairabanu, "A MultiWavelet Neural Network Particle Swarm Optimization Based MRPID of Interior Permanent Magnet Synchronous Motor Drives", International journal of Intelligent Engineering and System, Vol.9, No.3 pp.53-64, 2016.

[20] D. Mohan, X. Zhang, Gilbert, and H. Beng Foo, "Generalized DTC Strategy for Multilevel Inverter Fed IPMSMs with Constant Inverter Switching Frequency and Reduced Torque Ripples", IEEE Transactions on Energy Conversion, Vol. 32, No. 3, pp.1031-1041, 2017.

[21] P. Brandstetter, I. Neborak, and M. Kuchar, "Analysis of Steady-State Error in Torque Current Component Control of PMSM Drive", Advances in Electrical and Computer Engineering, Vol. 17, No 2, pp. 39-46,2017

[22] Q. Liu and K. Hameyer, "Torque Ripple Minimization for Direct Torque Control of PMSM with Modified FCSMPC", IEEE Transactions on Industry Applications, Vol. 52, No. 6, 2016.

[23] N. V. Naik, A. Panda, and S. P. Singh, "A ThreeLevel Fuzzy-2 DTC of Induction Motor Drive Using SVPWM", IEEE Transactions on Industrial Electronics, Vol. 63, No. 3, pp.14671479, 2016.

[24] T. P. Naidu and V. Kumar, "An Improved Direct Torque Control for Three-Level Inverter Fed Induction Motor Drive", International Journal of Engineering Research and Applications, Vol. 3, No. 6, pp.1206-1213, 2013.

[25] Y. Lamia, B. Sebti, N. Farid, C. Mihai, and P.L. Guasch, "Design of an Adaptive Fuzzy Control System for Dual Star Induction Motor Drives", Advances in Electrical and Computer Engineering, Vol. 18, No. 3, pp. 37-44, 2018.

[26] D. K. Kumar and G. T. R. Das, "Performance of Fuzzy Controller based Three Level Direct Torque Control fed IPMSM", International Journal of Engineering and Advanced Technology, Vol. 8, No. 3, 2019.
[27] R. Sharma, K. K. Pranjapat, and A. Sood, "Performance Analysis of Direct Torque Control of PMSM Drive Using Two Level Inverter", In: Proc. of IEEE. Conference on Communication and network Technologies, pp.7695-4692,2012. 